\title{
Research on the Development of Rural Family Farm: A Case Study of Shandong Province in China
}

\author{
Xiujuan Wang, Jilian $\mathrm{Hu}^{*}$ \\ School of Economics and Management, Shandong Agricultural University, Tai'an, China \\ Email: xjw9007@126.com, "Jlhu@sdau.edu.cn
}

Received 10 March 2016; accepted 16 April 2016; published 20 April 2016

Copyright (C) 2016 by authors and Scientific Research Publishing Inc.

This work is licensed under the Creative Commons Attribution International License (CC BY).

http://creativecommons.org/licenses/by/4.0/

(c) (i) Open Access

\section{Abstract}

In recent years, the rural family farms in Shandong Province of China have been developing very fast. They have achieved remarkable economic effects on improving the technical and equipment level of agricultural production, farmers' professional quality, the efficiency of land production and farmers' income-increase, etc. However, there also exist the problems of non-smooth land transfer, unclear farm recognition-standard, more difficult loan-financing, imperfect social service and so on. This paper suggests that measures should be taken to deepen the reform of the rural land system, perfect the land transfer mechanism, clarify the family farms confirmed standards, improve the family farms and financing system, perfect the socialized service system, and thus create a relaxed environment and conditions for the development of family farms in order to promote its healthy development.

\section{Keywords}

Rural Family Farm, Rural Land Transfer, Farms' Social Service, Agricultural Development

\section{Introduction}

In 2013, the top-level design of the management of the rural economy in China clearly put forward statutes to strengthen support on rural family farm ${ }^{1}$. In 2014, it further proposed to speed up the cultivation of new agricul-

\footnotetext{
"Corresponding author.

${ }^{1} 2013$ No.1central document: a number of opinions on accelerating the development of modern agriculture to further enhance the vitality of rural development.
} 
tural business entities including rural family farms ${ }^{2}$. In 2015, the scale of the rural family farm, which encouraged the development of the scale, was put forward again. ${ }^{3}$ It is clear that the development of family farms has become a national will. So, how about the development of farmer family farm in practice? Taking Shandong Province of China as an example, this paper has done research and analysis, and can partly answer this question. This paper suggests that measures should be taken to deepen the reform of the rural land system, perfect the land transfer mechanism, clarify the family farms confirmed standards, improve the family farms and financing system, perfect the socialized service system, and thus create a relaxed environment and conditions for the development of family farms in order to promote its healthy development.

\section{The Rise and Development of Rural Family Farm in Shandong Province}

Rural family farm is the new agricultural corporate entity, which regards family members as the main labor force, engages large-scale, professional farming activities, and treats agricultural income as the family's main source of income. Family farm has differences with the long-existed contractor [1]. Their linkage lies in the following aspects: they are operated within an individual family unit to engage in large-scale professional agricultural business activities, they rent rural collective-owned land or lease other farmers' contracted land, they all treat family members as the main labor force and treat agricultural income as the main source of family income. The difference between the two is that family farm is registered in accordance with the law of the agricultural legal entity while the contractor does not have a formal legal contract, and is just a farmer. According to the "Family Farm Registration Act (which was implemented in May 2013 in Shandong Province)” pointed out that the registration of family farms should be in line with four conditions: First, the family farm operators should be with rural household registration. Second, family members should be the main labor force. Third, agricultural income should be the main source of family income. Fourth, the operating scale is relatively stable, the land is relatively concentrated and contiguous, the land lease or contract period should be in 5 years or above and the scale of land management should meet the requirements stipulated by the local agriculture department.

In a dynamic view, the development of the family farm is still relatively fast. On the one hand, the number of family farms is increasing; on the other hand, the size of the family farm is constantly expanding.

According to the statistics gained at the end of 2012 (gained from the data from Shandong Provincial Agricultural Department), Shandong Province has 204 family farms, which are distributed in 14 cities and 36 counties. The types are given priority to crop farming, aquaculture and the combination of farming-aquaculture. Among them, the ones that are dominated by farming, reaches 50, their planting area reaches 27,662 mus ${ }^{4}$, and the largest single households' planting area is 5,030 mus, while the minimum planting area is 12 mus [2]. The one, which is dominated by aquaculture, reaches 46 ; the largest aquaculture area is 4,050 acres and the smallest one is 60 mus. ${ }^{5}$

In May 2013, Shandong Province first took the lead in the country and issued a "Family Farm Registration Act”, which provides institutional support for registration and establishment of family farms for farmers all around [3]. This action has a strong impetus to the development of family farms in Shandong Province, and its size and number reached the momentum of rapid growth from then on. According to statistics in May 2013, the number of officially registered family farms in Shandong Province is 1,188 and is 5.8 times of that in 2012. The registration forms of farm household are diverse. Among them, 1,116 are registered in the form of individual industrial and commercial households (accounting for $94 \%$ of the whole number of farm household registration), 66 are registered in the form of a sole proprietorship enterprise, 5 are registered in the form of agricultural companies and one as the professional farmers cooperatives (in fact, it is not cooperatives because it has only one member) [4]. From the perspective of land management scale, the one who owns more than 200 mus of family farms have reached 419 (accounting for 35.27\%), the one who owns family farms between 50 mus to 200 mus reached 402 (accounting for 33.84\%), and the ones who own less than 50 mus reached 367 (accounting for 30.89\%) (gained from the data from Shandong Provincial Agricultural Database).

By July 2013, the number of family farms that received official recognition and registration in Shandong Province has increased to 2,484. With 1,296 newly added farms, it increased 1.1 times than two months ago.

\footnotetext{
${ }^{2}$ November 2014, the central office of the CPC Central Committee, the State Council Office: the proposals on guiding the orderly transfer of rural land management and development of agricultural moderate scale operation.

${ }^{3} 2015$ No.1 central document: on the reform and innovation to accelerate the construction of agricultural modernization.

${ }^{4} 1 \mathrm{mu}=0.165$ acre.

${ }^{5}$ Source: Shandong provincial agricultural department of rural economic management office.
} 
Family farms that are mainly engaged in farming and aquaculture accounted for $45.3 \%$ and $48.2 \%$ respectively. The one, which combined farming and aquaculture accounted for $4.1 \%$ and family farms which engaged in other industries accounted for $2.4 \%$. From the perspective of scale of operation, the ones whose operation scale is below 50 mus reached 1,560 (accounting for 62.80\%), the ones between 50 mus to 100 mus reached 414 (accounting for $16.67 \%$ ), the ones between 100 mus to 500 mus also reached 414 (accounting for 16.67\%) and the ones which operate more than 500 mus reached 96 (accounting for 3.86\%). ${ }^{6}$ Obviously, the size of the family farm has been significantly expanding [5].

In 2014, the number of rural family farms achieved significant increase again. By the end of 2014, the number of the registered family farms in the relevant departments has reached to more than 38,000, including 16,161 family farms which are formally recorded in agricultural sector. From the perspective of the type of industry, the ones that are engaged in farming accounted for $83 \%$, the ones that are engaged in farming-aquaculture accounted for $11.6 \%$, and others accounted for $5.4 \%$. From the perspective of land scale, the one whose operating area is 100 mus or below accounted for $54.5 \%$, the ones whose operating area is between 100 mus to 500 mus accounted for $42.5 \%$, and the one that owns more than 500 mus accounted for $3 \%$. From the point of operating income, the ones with the annual income of RMB 100,000 or below accounted for $48 \%$, the ones with the annual income between RMB 100,000 to RMB 500,000 accounted for 39.9\%, and the ones with more than RMB 500,000 accounted for $12.1 \%$.

\section{The Development Effect of Rural Family Farm in Shandong Province}

\subsection{Quick-Promote the Level of Technology and Equipment of Agricultural Production}

The mechanization of the family farm of Shandong Province has been strengthened and the technical level has been improved continuously. Until December 2014, the province's family farm has 28,066 agricultural machinery and the total power is 3630.71 megawatts, which includes 12,820 tractors, 2,698 combined harvester, 1,175 irrigation machines and 673 drying machines ${ }^{7}$.

In order to make their mechanical development go line with the yield increase, the Fu Min family farm (a family farm in De Ping village, Linyi County, De Zhou City) purchased a large number of advanced machinery, such as corn and wheat combined harvester, no-tillage planter, sub-soiler, more than 60 sets of deep plowing machines, and 160 motorized sprayers. They implement the mechanized operation, the scale of operations and try to lay a solid foundation for further development. In order to increase production and efficiency, the leadfarmer Wei Dedong visited the national advanced family farm demonstration model several times and has communicated continuously with the relevant technical staff. He has adopted advanced technology of agriculture, combines with the climatology, soil science and local condition and employs the scientific method to cultivate corn, wheat, etc. By doing so, his per unit area yield is $15 \%$ higher than others and the maize he yielded in 2014 reached 973.4 kg/mu. Thus, he has been honored as the “Shandong Grain King”. In addition, Wei Dedong also attaches great importance to scientific and technological innovation. He has established cooperative relations with Shandong Agricultural University, Shandong Academy of Agricultural Sciences, Dezhou Academy of Agricultural Sciences to bypass technology, introduce advanced technology and talents, vigorously promote advanced varieties and technology, and finally achieve high benefit and efficiency. While becoming rich, he did not forget to help other farmers. Being taught by his precept and example, the farmers around him also tasted the sweetness of the family farm and all have gained good harvest. He influences and leads six surrounding villages to achieve a breeding area of more than 8000 mus, and actively signed orders with foreign enterprises. Reducing the risk of planting, they guarantee the local corn can be sold abroad and each with RMB 0.2/kilogram higher than the market price. All of this not only can enhance the farming efficiency but also create greater profits for farmers.

\subsection{Significantly Improve the Professional Quality of the Practitioners}

The rapid development of family farms attracts and nurtures many new professional farmers with higher education level. Liu Tao, a returning entrepreneur in Dayang village, Dongping county, Tai'an City, Shandong province, graduated as a biotechnology major from Zaozhuang College in 2013 and returned to the countryside that

\footnotetext{
${ }^{6}$ Source: Shandong provincial agricultural department of rural economic management office.

${ }^{7}$ Data sources: Shandong Province agriculture machinery management office.
} 
year. Utilizing the knowledge and skills gained in the university and by land-transfer, he founded a new farm with more than 400 mus of planting base. His farm mainly plants vegetables and he tries to develop featured organic farming. In 2014, Liutao cooperated with Tai'an Asian Organic Vegetable Company and made orders for large-scale organic vegetables. In spring, they planted 300 mus of soybeans, 40 mus of carrots and 90 mus of green beans. In autumn, they planted 300 mus of broccoli and 150 mus of spinach. By this kind of order-production and order-sale, they achieved the high quality and efficiency of agricultural production and net gain farm income of RMB 150 million for the entire year.

Yuanquan, who graduated from the College of Art and Design at Nanchang University in 2013, decided to abandon his previous work in Shenzhen and returned to his hometown in Zaozhuang, Shandong Province. He raised funds of 5 million, and opened a family farm (Longtan Family Farm) with 500 mus. It mainly produces vegetables and fruits. This is also the first family farm in Shandong Province with independent legal qualification. Yuan Quan believes the production of fruits and vegetables should take the high-end route and must be sold in large cities. It also can engage in appropriate deep processing to establish their own brand.

\subsection{Promote the Efficiency of Land Production and Farmers' Income}

The development of land transfer and the family farm optimize the allocation of rural land resources structure, promote the farmlands' scale operation, mechanized farming, standardized production, as well as improve the land productivity and efficiency. For example, the Hanting District of Weifang City, their output value of the land is increased by $261 \%$ after land transfer. Besides the benefit gained from land-transfer, the farmers can go out to work or become the employee of the transferee to earn a wage income. Judging from the current situation of most regions in Shandong Province, the land rent is generally between RMB 800/mu to RMB 1500/mu and the wage income received by working is usually between RMB 80 to RMB 150 per day in between.

“Xing Nong Family Farm” in Xizhang town, Tai'an City is located in the northeast of Donghan village, Xizhang town in Tai'an City, Shandong Province. Its major development industry is forestry and fruit, which belongs to apple planting area. The lead-farmer Li Bingting, acknowledged the state's current family farm policy from TV. After land-transfer, he contracted 54 mus of land and first registered the first family farm in Tai'an City. By applying advanced irrigation technology, they greatly improved the efficiency of planting and promoted the agricultural income and efficiency. Due to the viscous soil and the weak drainage capacity during the rainy season, the lead-farmer Li Bingting consulted the professors in Shandong Agricultural University many times. Under the professors' careful supervision, he creatively applied an "Underground Drainage Method" throughout the farm, i.e. bury PVC pipe under the fruit tree roots and punch enough round holes. Thus by doing so, it can promote crop root respiration while draining off the water, which can ensure a substantial increase in the yield of fruit. The farm mainly adopts the watering-fertilization method called "fertigation". It is a method to dissolve fertilizer in water in advance and then use the dropper for irrigation and for the nutrients. It takes only several hours to finish the irrigation and fertilization for the whole farm. This can save manpower and material resources, as well as save resources and improve efficiency of the fertilizer. In addition, in Dongping County, Tai'an City, there is a lead-farmer called Tang Xianlei, who engaged in agricultural production for nine years. When the government issued the policies, he earnestly studied the policy and found the business opportunities. With a registered capital of RMB 120 million, 260 mus of land, 6 sets of various kinds of agricultural machinery, and 3 transport machines, he immediately registered the "Datang Family Farm”. His farm belongs to the type of farming-breeding, which mainly develops crop planting, as well as livestock and poultry breeding. The typical characteristic of his family farm is to create their own brands, which break the image of Chinese agricultural products as "no brand product". It immediately improved the market visibility and market share and increased profits.

A characteristic of the Hong Feng Ecological Family Farm (which is located in Dongchang Fu, Liaocheng City) is pollution-free. The ecological agriculture is mainly divided into two types: one is pollution-free, selenium-rich vegetables and ecological picking-garden. The scale of the "pollution-free and selenium-rich" vegetables is about 100 mus, which plant a variety of non-seasonal vegetables. In order to meet peoples' increasing consumption demand, they register their own brands and develop scale marketing. What's more, they open up 80 mus of trusteeship vegetables to provide opportunities for people in the city to create their own vegetable garden--a wise choice to engage in ecological tourism. An ecological picking-park is about 150 mus and the main planting including a dozen varieties of round bell strawberry, jujube, and walnut and cherry trees, which 
can attract city people to the farm to enjoy sightseeing, tourism and picking. They are eager to build a green ecological garden that combines sightseeing, picking and catering. This kind of service chain can definitely promote the development of family farms and improve its economic efficiency.

\section{New Problems Aroused in the Development of Rural Family Farm}

\subsection{Land Transfer Is Still Difficult in the Process of Setting up Family Farm}

Land transfer is the premise and foundation of developing a family farm. However, in some areas of Shandong Province, the issue of land transfer is still the first obstacle to the development of family farms [6]. By visiting and making field investigations, we conclude that the reasons for the difficulty of land-transfer are as follows.

First, there is non-standard procedure. At the present stage, most parts of the land transfer in Shandong Province are only by verbal agreement. The procedure of land transfer is highly abnormal, and there is no formal contract for the land transfer, which to a certain extent affects the transfer of the land. In addition, farmers in our country have a sense of pity towards land, so when the land transfer procedures are not standard and inadequate, it definitely will cut enthusiasm and motivation of farmers' land transfer.

Second, due to the implementation of agricultural subsidies in China in recent years, many farmers have realized that the land should be kept even if it is not used, because they could receive a certain annual subsidy for the ownership of the land. Therefore, we could easily see that in many places in Shandong Province no one is willing to cultivate some of the land even if it is barren. For receiving agricultural subsidies, some of the transferred land has been returned. Therefore, to some extent, those factors all contributed to the difficulties of land transfer.

Third, the rent of land transfer has increased. According to farmers' reaction in most parts of Shandong Province, the rent of land transfer is becoming more and more expensive. In the past few years, the rent of land transfer is RMB 300/mu to RMB 500/mu, but now it would increase to RMB 800/mu or even RMB 1000/mu. As a result, it becomes a problem for those whose profit margin is lower. The conflicting fact is that when the rent is less, the farmers are unwilling to rent their lands, when the rent increases, the farm operator cannot bear the lower profit.

Fourth, the land transfer does not achieve the purpose of centralization. For the development of family farms, only but the scale operation can reduce production costs and further facilitate management to achieve the expected benefits. However, the land of the scale operation is transferred from farmers one by one and in the process of transfer, detailed motivational work should be done household after household, so it is inevitable that there are some farmers who are reluctant to transfer no matter how high the rents are. As a result, all the previous efforts will be wasted for it cannot achieve scale operation.

Fifth, the operating period of transferred land cannot be unified. Most of the family farm operators treat the farm as their own career to develop, and they hope to have a long-term business and expect a long-term fixed operating period. At the present stage, farmers' remaining contract period is almost 20 years or so, but it is still difficult to rent the family farms even only for five years. Some of the farmers are only willing to loan for three years or only one year, even if it is in accordance with the floating chain price rent. They do not prefer to sign a long-term land transfer contract, or someone may get back his land before the contract limit, which will lead to the great difficulty of land transfer. What is worse, they may have some conflict during the contract period, which will definitely affect the normal operation of the family farm.

Sixth, the crowding-out-effect of the industrial and commercial capital to the family farm land transfer. Compared with industrial and commercial capital, the income of agricultural business is relatively low, and family farms far exceed their power when compared with the one-time higher payment gained by industrial and commercial capital go-downtown. Farmers are more willing to lease the land to industrial and commercial enterprises rather than family farm, which will lead to the difficulty of the family farm land transfer and the crowdingout-effect becomes apparent.

\subsection{Lack of a Definite Identified Standard for Family Farms}

By investigation and face-to-face interview, conclusions can be drawn that the majority of the masses and leadgrower all have great expectations on the development of family farm, but they are fuzzy about the defining standard of family farm. There exist several problems in the standard of identification. 
The size of the family farm is not clearly defined. Shandong Province and its local governments have not yet published the identification standard of the size of family farms, so farmers do not know how much the size of the family farm can be called family farm and can be registered. The actual situation varies in different regions, so the specific definition of family farm will be different accordingly, which will lead to the ambiguous definition of farmers' family farm.

The standards for government subsidies are not clearly defined. In order to facilitate the development of family farms, many areas will take some subsidy measures on the family farm, but there are no clear standards for those subsidies. As a result, farmers do not know how big the scale of operation can get subsidies and by what criteria can they obtain the subsidies.

There may exist the phenomenon of "pretending-family farms". Due to the states vigorous development and support for family farms, there will be some corresponding subsidy measures. Under these circumstances, some cooperatives or organizations will try to obtain the corresponding subsidy by changing their names for family farms, thus some family farms appear that don’t deserve the name.

\subsection{The Loan Financing of Family Farm Is Still Difficult}

The development of family farms generally requires a lot of financial support. By visiting and making surveys, we found that the credit system of Shandong Province is not perfect. Farmers' loan financing have been greatly restricted. The main problems are listed in the following aspects:

The channel of loan financing is relatively single. From the investigation of the family farm in Shandong Province, we could easily find that the rural credit cooperatives are the main channel for family farm's credit, as well as individual private credit. Those can be concluded that the resources of family farm credit in Shandong Province are relatively single. Due to the low-efficiency and the slow-profit of agricultural production and no real assets as collateral, it is very difficult to obtain a secured loan from the bank. What can be done is to seek a low-amount and short-term coordinated loans from the credit cooperative. However, when urgent needs on capital are encountered, the farmers are often helpless and full of anxiety.

The financing difficulties caused by credit problems. Under the incomplete credit system in China, farmers' credit is not high enough to meet the financing difficulties. In this case, the credit society takes high interest rates and the loan rate is twice as much as the international benchmark interest rate, which increases the operating costs of the farmers to a certain extent. The credit problems can also lead to the insufficiency in the loan amount. Some credit unions may offer the loan to the farmers, but the amount is so small that they cannot meet the actual needs of the family farm.

The financial institutions implement single-family management and set quotas, in which most of them cannot meet the financing needs of farmers. What's more, the condition is very harsh and the approval process is quite complicated so that many farmers even choose private loans with higher-interest rates to raise funds. For example, the rural credit cooperatives in Dezhou City set a maximum loan limit of RMB 1.5 million for farmers. Jining Agricultural Bank allows farmers to limit the maximum loan for RMB 50,000 and the rural credit cooperatives in Laiwu City provide RMB 200,000, which are far from being meet the financing needs of farmers. Under these circumstances, most of the farmers raise funds via "self-financing plus bank loans plus private loaning".

\subsection{The Social Service System of Family Farm Is Still Not Perfect}

The development of family farm is inseparable from the social service system because a good social service system can promote the rapid development of family farms, but imperfect system will constrain its development. At present, the social service system in Shandong Province is not sound and there are still aspects that need to be perfected. The main problems in this stage are as follows.

On one hand, the professional-technical personnel and knowledge are the bottleneck of their development. The family farm is a new professional and large-scale agricultural cooperation organization. Its development requires the guidance of specialized talents and the support of professional-technical knowledge, but the development of the rural areas in our province generally lacks the guidance of professional-technical personnel, which greatly restricts its scale production.

On the other hand, the agricultural service mechanism is not perfect. Sound mechanisms for agricultural services can save the production costs, improve production efficiency and eliminate the worries of family farm operators. However, most areas in our province have not established sound mechanism for agricultural services. 
They cannot reach the standard of unified-purchase of agricultural products and the ability to control the system is slightly poor. Although the government has established the social service systems in some areas, the personnel of the existing public service organization become aging. Additionally, their service level is not high and the coverage of the service is limited. As a result, there is an urgent need for enhancing the service ability of unified control, drought-resistance, drainage, product purchase and sale.

What's more, social service system lacks the strong policy-support. The establishment of a sound social service system cannot be separated from the government's policy support for a variety of professional services organizations. But for a number of professional service organizations in most parts of Shandong Province, it is difficult for them to apply the talents and technology to the fields and they cannot play various roles as a specialized service organization due to the lack of support of corresponding policy and sound mechanism. Local governments in some areas just issued policy information related to the family farm. There are relatively few consulting and guidance services and they lack the tracking survey of the implementation condition of the policy and effective evaluation, which result in some policies only being decoration and cannot have the actual effects.

\section{Conclusion and Recommendations}

According to the relevant issues listed in the previous parts, some related recommendations for promoting the development of family farms are given as follows.

\subsection{Establishing and Perfecting the Land Transfer System}

Firstly, the land reform should be deepened. The current Chinese policies are benefit to the transfer of land and the development of family farms, such as the long term unchanged land contract policy and the land ownership policy. In the future, we should emancipate our minds and deepen the reform of the land system to promote the transfer of land from these several aspects [7]. On one hand, it is necessary to clarify the ownership right of land and issue niche targeting laws of land transfer. Further clarifying farmers' right of land contractual management, issuing operating warranty, letting farmers transfer land, invest and cooperate in business in accordance with the law are necessary. For example, the Songjiang mode is strongly promoted in our country now. One of the important premises of the development of this family farm is the property rights reform of the rural collective economy. The land owned by Songjiang family farm operators has three “obligees": the proprietary rights belong to the collectives, the contractual rights belong to the villagers who have specific land rights, and the management rights belong to the lead-farmer in the family farm. Although there are many side effects for this kind of spontaneous transfer system, their experiences are still useful for reference [8]. Therefore, governments should issue niche targeting and binding laws and regulations for land transfer as soon as possible to promote the clarity of land proprietary rights, and let the family farms gradually have more and more land to cultivate. Only then can the farmers be willing to invest more in the land and improve family farm's economic efficiency. Then, regulating land transfer procedures and drawing up unified land transfer contract are essential. At the present stage, Shandong Province does not have a unified land transfer contract. It should regulate land transfer through regulating a land transfer contract, introducing systems such as access audit in advance, and supervision and management in process to protect rights of both sides. Finally, we should establish a family farm registration system as soon as possible. Now, in some areas of Shandong Province, the identification criterion of the family farm has been established. For example, in Zhucheng City in Shandong Province, they have established "Interim Measures of Family Farms’ Identification and Management” [9]. It defines what kinds of business entities are family farms, and how to make identity qualification and industrial and commercial registration, etc. But there are still a variety of cities in Shandong Province that haven't specified a clear family farm registration system. This should be established as soon as possible in order to give family farms a clear identification.

Secondly, we should establish and perfect transaction and service platforms for land transfer. On the one hand, in order to promote the orderly and legal land-transfer to make family operators freely invest and operate, the following aspects should be implemented in a timely manner: a convenient and efficient information registration system of land transfer, a contract standardization signing system, a security system of compensatory transfer, and an arbitration institution of dispute mediation. One the other hand, information sharing should be achieved to stimulate development. Feedback of registered information should be timely delivered in a timely manner to the agricultural-financial sector, financial institutions, agricultural policy insurance services sector, and other departments. Coordination with relevant departments to make family farms into the scope of compensation to 
ensure better land-transfer is also necessary.

Thirdly, set a unified land transfer period [10]. The non-unified land transfer period will bring great difficulties to the management of family farm. Therefore, local governments in different areas should formulate a unified land transfer period according to their actual situation and sign a unified land transfer contract. On the other hand, the land transfer costs should be adjusted according to the market price of agricultural products. Government should increase subsidies to land transfer in order to promote the reasonable transfer of land. Songjiang set a good example for other cities. The income of land transfer is RMB 500 per mu and will be raised in the proportion of the increase of grain prices, which provides necessary stabilizers for land transfer. Not only can this ensure farmer's land transfer, but also ensure the active operation and management of family farm's contractors.

\subsection{Clarifying the Criteria of Identifying Family Farms}

A registration system of family farms should be established as soon as possible to clarify the standards of identification. Different areas should make standards of identifying according to their specific situations. Different types of family farms should have different standards, just as the five typical samples of developing family farms in our country. The mini family farms, which owns more than 50 mus, such as the example in Ningbo City, Zhejiang Province and Langxi county in Anhui Province. The middle family farm in Songjiang, Shanghai and Wuhan, Hubei Province. The family farms in Songjiang, Shanghai City are between 100 mus to 1500 mus while the farms in Wuhan, Hubei Province are between 50 mus to 500 mus. The average operating areas of large family farms (such as Yanbian, Jilin Province) are 1,275 mus. Another example is the "Interim Measures of Family Farms' Identity and Management” which was published in Zhucheng, Shandong Province. According to the measures issued, the scale of the family farms can be divided into mini-farm, middle-farm and large-farm. To industrial types like planting, breeding and a combination of these two kinds, it also makes specific standards for its area, livestock population, slaughter rate, income and other criteria respectively. Identified family farms must meet standards required. Therefore, local governments should set their own identification criteria according to their own specific circumstances and some domestic experience. The criteria should be with local features and should not be one-size-fits-all criteria.

We should clarify the size of the family farm. In the scale of family farms, it should have small family farms like Songjiang, Shanghai City, whose operation land is between 100 mus 150 mus. It should also have large family farms like Yanbian, Jilin Province, whose operation land is 1,275 mus in average. Dang Guoying, director of the Chinese Social Science Institute of Rural Development Macro Office, claims that if taking a variety of factors into account, the scale of most family farms in the plain areas should not exceed 300 mus for planting main crops and not exceed to 30 mus for growing vegetables. Those considering factors are the speed of the transfer of surplus rural labor force, the management level and the existing technical equipment and supporting service system, etc. If the scale is too large, there will appear land subcontract for the second time. The reality of China's small-scale farm economy also determines that China's family farm will follow the Songjiang mode (small family farm) in the long run. But Sheng Yafei, Songjiang District Party committee secretary, also pointed out, "We had estimated that if the couple are young workers, they can cultivate 600 mus of land according to the current labor productivity. That is to say, only five hundred or six hundred farmers are needed for the current 300,000 mus of land in Songjiang, of which 200,000 mus are rice. This is the goal of our family farm.” With the expansion of the scale of the family farm, the management of the farm may break through the limitation of "Treat Family as the Production Unit". The specific situation of each region in Shandong Province is different. Criteria of the scale of family farm should be made by taking into account the labor employment, the flow of the labor, as well as the economic situation in each city.

\subsection{Promoting the Innovation of the Financing System of Rural Family Farm}

Measures should be taken to promote the innovation of the financing system. Perfect the credit system and reduce the difficulty of family farm's financing should be the first choice. On the one hand, measures should be taken to strengthen the intensity of traditional rural commercial bank credit to support and benefit agriculture. Government should give appropriate preferential tax according to qualification, development direction, and current performance of the family farm. On the other hand, agricultural financing channels should be expanded through the development of rural small loan companies and other non-traditional financial credit inter-mediation, thus to solve the problem of agricultural production financing difficulties. The threshold should be further re- 
duced and rural mutual-help funds, small loan companies and rural banks, etc, should develop vigorously. Actively explore the establishment of agricultural credit guarantee company is critical. In order to alleviate the problem of financing of family farms, loan guarantees should be provided by means of government-funded, social capital and enterprise operation.

Innovate the financial products of family farm should be a second choice. The financial sector should try to innovate collateral means and ways of financing, such as providing mortgage for farm machinery for the agricultural specialist; carrying out supply chain finance to family farms with high degree of industrialization to innovate agricultural order financing; issuing credit loans for those family farms with higher credit status, and so on. Land is an important property of family farms, and strengthening the financial support of family farms needs to develop land finance. So, we should break through the legal barriers of land financing, try to modify the "Law of Warranty" and other related laws to allow mortgage financing for utility rights or contractual management rights of the rural collective land. Government should speed up the registration of rural land property rights, establish and improve the market of rural land transactions and develop assessment agencies of rural land property value to create conditions for land financial innovation.

\subsection{Improving the Social Service System of the Rural Family Farm}

Proper measures should also be taken to improve the social service system of the family farm. Improve service levels in the stage of family registration approval would be the first choice. Simplify the examination and approval procedures, limit the handling time limit of the registration. Government should set up the prioritypass-channel for family farms registration, and should provide one-stop registration and approval service as well. A summary of the research and investigation of family farm should be made and door-to-door tracking service should also be provided for the registered family farm.

Achieve information-sharing to promote development vitality would be the second choice. The registration information should provide timely feedback to agriculture and financial sector, financial institutions and the Insurance Services Department concerning agricultural policy. Coordination should be made with the relevant departments to ensure the incentives and subsidy for family farms thus to guarantee their land transfer, agricultural machinery purchasing etc. Strengthening support services for family farm should be worked out quickly.

Establishing and improving the agricultural insurance system to further expand the agricultural insurance coverage would be the third choice. Different types of insurance should be set according to characteristics of family farm business in order to reduce the economic loss caused by fluctuations in market prices and natural disasters.

Taking full advantage of the professional-technical personnel and technology of the related Agricultural Department to establish stable guiding and cooperative relations with farmers, family farms and rural professional cooperative organizations would be the fourth choice. Innovate the construction of the service system in agricultural technology, agricultural extension, do well in introduction and promotion of modern agricultural technology achievement, strengthen the training of practical skills of farmers, in order that farmers can consciously participate into the construction of modern agriculture. To further improve the agricultural technology extension system, promote the construction of new agricultural social service system is also crucial. Only by this way, can government guide the family farm to use advanced agricultural technology, to plant high-yielding new varieties, to carry out scale business and to make standardized production.

\section{Acknowledgements}

This paper is supported by the Major Research Projects of Agricultural Science and Technology Innovation in Shandong Province.

This paper is supported by Project of Education, Science and Research of Shandong Province (No. 15SC105) and Social Science Project of Shandong Agricultural University (No. 23899).

\section{References}

[1] Gao, J.B. (2006) From the Household Contract System to the Farm System: The Second Leap of Agricultural Development in China. Journal of Tianjin University of Commerce, 5, 28-32

[2] Huang, Y.T. (2010) The Path Selection of Family Farms and Farmland Scale Advantage. Chongqing Social Sciences, No. 5, 20-23. 
[3] Li, X.L. and Wang, J.K. (2010) The Realization of Agricultural Organization: Family Farm. Journal of Anhui Science and Technology University, No. 4, 91-94.

[4] Wang, X. (2013) On the Construction of the Chinese Family Farm. Economic Research Journal, 4, 12-16.

[5] Le, Z.Z., Jian, F.J. and Hu, H.M. (2012) “Company + Family farm” in the Modern Agricultural Production and Operation Mode: Based on Wen’s Group Case Study. Academic Research, 3, 25-35.

[6] Zhao, W.Q. and Zhi, J. (2012) Analysis of Family Farm Business Model Innovation and Social Service Mechanism in Zhejiang Province. Agricultural Economy, No. 7, 39-41.

[7] Zhu, X.X. (2006) Family Farm Is a Realistic choice For Agricultural Intensification Management in South of Jiangsu. Agricultural Economic, No. 12, 58-62.

[8] Chen, J.P. (2012) Analysis on the Scale of Agriculture in China from the Perspective of Organization. China Economic, No. 6, 75-79.

[9] Liu, Q.J. (2014) Shandong Family Farm in Shouguang City, Province Development Present Situation and Countermeasure Research. Shandong Agricultural University, Tai'an.

[10] Liu, J.L. (2014) Analysis of the Land Circulation Influence Factor in Shandong Province. Chinese Journal of Agricultural Resources and Regional Planning, No. 6, 32-38. 